\title{
Spatial and depth-resolved studies of air plasma-sprayed hydroxyapatite coatings by means of diffraction techniques: Part I
}

Tshepo P. Ntsoane ${ }^{1,5^{*}}$, Mira Topic ${ }^{2}$, Margit Härting ${ }^{3}$, Robert B. Heimann ${ }^{4}$, Chris Theron ${ }^{5}$

${ }^{1}$ Research and Development Division, NECSA Limited, P.O. Box 582, Pretoria, 0001, Gauteng, South Africa, tshepo.ntsoane@necsa.co.za

${ }^{2}$ Materials Research Department, iThemba LABS/National Research Foundation, P.O. Box 722, Somerset West, 7129, Cape Town, Western Cape, South Africa, mtopic@tlabs.ac.za

${ }^{3}$ Department of Physics, University of Cape Town, Rondebosch, Private Bag, 7701, Cape Town, South Africa, margit.harting@uct.ac.za

${ }^{4}$ Am Stadtpark 2A, D-02826 Görlitz, Germany, robert.heimann@ocean-gate.de

${ }^{5}$ Department of Physics, University of Pretoria, Lynnwood Road, Pretoria, 0002, Gauteng, South Africa, Chris.Theron@up.ac.za

* Corresponding author.

Necsa

P.O. Box 582

Pretoria

0001, Republic of South Africa

Tel.:+27 12305 5400; Fax: +27 123055851 


\begin{abstract}
Hydroxyapatite coatings ( $\left.\mathrm{HAp}, \mathrm{Ca}_{10}\left(\mathrm{PO}_{4}\right)_{6} \mathrm{OH}_{2}\right)$ were deposited by air plasma spraying onto Ti6Al4V substrates and investigated to determine the depth-dependent behaviour of phase composition, crystallinity, and residual stress using diffractometric techniques. Throughthickness characterisation was carried out by conventional X-ray and synchrotron radiations in reflection and transmission geometries. Results showed HAp together with its thermal decomposition products, tetracalcium phosphate (TTCP), tricalcium phosphate (TCP) and calcium oxide to be present throughout the coating thickness. Quantitative phase identification employing Rietveld refinement showed HAp and TTCP to be the two major phases, with the former decreasing with depth whilst the latter increases. The largest changes were observed adjacent to the coating-substrate interface region. Crystallinity investigation showed a similar trend, revealing a more crystalline near-surface region and increasing amorphisation toward the coating-substrate interface. Residual stress investigation revealed the normal components $\sigma_{11}$ and $\sigma_{33}$ to be tensile and compressive, respectively. The stresses relax and increase to respective minimum and maximum within the first $145 \mu \mathrm{m}$. With further penetration depth, both normal stress components became tensile.
\end{abstract}

Keywords: Plasma-sprayed hydroxyapatite coatings, X-ray diffraction, Quantitative phase analysis, Degree of crystallinity, Residual stress. 


\section{Introduction}

Hydroxyapatite (HAp), owing to its similarity to the mineral component of bone, has been extensively studied as a candidate material in biomedical applications, ranging from filling of bone cavities [1] and artificial eye components [2] to coatings for hip and dental implants for improved biological fixation [3]. However, the poor mechanical properties of hydroxyapatite limit its bulk utilisation in fully load-bearing applications. In such cases, the material is applied as a coating on metallic substrates such as $\mathrm{Ti}$, Ti alloys and CoCrMo, thereby combining the excellent mechanical properties of the metal with the osseointegration ability of the bioactive, i.e., osseoconductive bioceramic material $[4,5]$. There is a plethora of coating techniques applied to depositing hydroxyapatite [6]. Although on an industrial scale thermal spraying is still the technique of choice to deposit hydroxyapatite powder on the metallic substrate (see, for example [7-12]), the high temperature of the plasma generally results in thermal decomposition of the material, leading to reduction in crystallinity [13] and introduction of undesirable thermal decomposition products [14], respectively. The latter include phases such as tricalcium phosphate (TCP), tetracalcium phosphate (TTCP), and sometimes calcium oxide. These phases are known to be susceptible to dissolution in simulated body fluids $[15,16]$ and thus may compromise the mechanical stability and integrity of the coating. In addition, higher amounts of cytotoxic calcium oxide will impede osseointegration.

Although extensive investigations have been carried out on HAp coatings [6], the bulk of the work has focused on the near-surface region, i.e. the region in immediate contact with living tissue. For instance, coating investigation employing 8-keV conventional laboratory X-rays to study the effect of simulated body fluid on phase composition of plasma sprayed HAp [17] and residual stresses [10, 18], mechanical properties of the coating [19], the effect of heat 
treatment on phase changes and crystallinity [20] have all been limited to about the first 20 micrometres of the coating. Probing the coatings with protons, e.g. in micro-PIXE for element distribution analysis [21] leads to an even shallower depth penetration. Depth profile investigations carried out thus far have been few and far between. Of those investigations, mainly destructive techniques such as layer removal methods were employed [22]. This of course has an inherent potential drawback in that sample preparation may affect some aspects of the results, in particular stress measurements. Other techniques also focussing on the coating surface include scanning electron microscopy for microstructure characterisation [23]. Although these studies provided crucial information albeit depth limited, their usefulness has been reduced by lack of quantification. In this work, results are presented of a comprehensive spatial and depth-resolved investigation of phase composition, crystallinity, and residual stress distribution of air plasma-sprayed HAp coating employing non-destructive X-ray and synchrotron radiations. The forthcoming part II of the study will present similar results extended to solid rod samples designed for fatigue tests.

\section{Materials and Methods}

\subsection{Sample preparation}

Hydroxyapatite powder (CAPTAL 90, batch P215, Plasma Biotal Limited, Tideswell, Derbyshire, UK) with size distribution of $120 \pm 20 \mu \mathrm{m}$ was plasma-sprayed onto medical grade Ti6A14V alloy supplied by Biomaterials Limited, North Yorkshire, UK. The substrates were $5 \mathrm{~mm}$ thick discs cut from a $20 \mathrm{~mm}$ diameter rod. Prior to spraying, they were gritblasted with alumina particles of irregular shape with sizes ranging between $0.5 \mathrm{~mm}$ and 1 $\mathrm{mm}$. Subsequently, the substrates were cleaned ultrasonically for $10 \mathrm{~min}$ at $40^{\circ} \mathrm{C}$, using a $10 \%$ 
Tickopur® solution in deionised water. Plasma spraying was performed without substrate cooling under atmospheric conditions, using a PT M-1000 (Plasmatechnik, Wohlen, Switzerland) system equipped with a Sulzer Metco F4 MB plasmatron. The powder was injected externally into the plasma, $90^{\circ}$ to the direction of the plasma jet axis. Details of the coating parameters are reported in Table 1.

\subsection{Near-surface coating characterisation}

For coating characterisation, X-ray diffractometry available at NECSA's X-ray laboratory was employed. Phase identification measurements were carried out using a Bruker D8 ADVANCE diffractometer equipped with a theta-theta goniometer. Beam optics included a Goebel mirror on the primary side and Soller slits on the secondary side. Measurements were carried out at the geometrical centre of the as-received sample's top surface. A copper tube operated in line focus mode was used for analysis and the diffracted data were collected using a compound silicon strip technology-based 1-D Lynx Eye detector. Qualitative and quantitative phase identification was carried out using the manufacturer's proprietary Eva v13

software (BRUKER AXS, Diffrac ${ }^{\text {plus }}$ Basic Evaluation Package Release 2007) and TOPAS v4.2 software (TOPAS-ACADEMIC v4.2, Coelho Software, Brisbane, Australia, 2007). The latter was also used for crystallinity evaluation. Additional phase identification measurements were carried out at the $2^{\text {nd }}$ generation Laboratório Nacional de Luz Síncrotron (LNLS) facility, Campinas, Brazil. Measurements were done, on the same sample with the same orientation, using $11 \mathrm{keV}$ synchrotron radiation at the D10A-XRD2 beamline. The beam source was a $4^{\circ}$-bending magnet with energy resolution $\Delta \mathrm{E} / \mathrm{E}$ of $1.3 \times 10^{-4}$ [24]. Data acquisition was done with a 0 -D-scintillation detector. The beam size at the sample surface was $0.6 \mathrm{~mm}$ height by $1 \mathrm{~mm}$ width. 
The corresponding near-surface residual stress was investigated using a Bruker's D8 Discover equipped with a $1 / 4$ Eulerian cradle with the primary side optics including a graphite monochromator and a $0.8 \mathrm{~mm}$ collimator. Measurements were done using a copper tube operated in point focus mode, employing the $\Psi$-tilting method. Sample was measured in side inclination geometry with sample rotation axis in the diffractometer plane. For a full stress tensor determination, measurements were done at eight tilting angles $\psi=0^{\circ}, 10^{\circ}, 20^{\circ}, 30^{\circ}$, $40^{\circ}, 50^{\circ}, 60^{\circ}$ and $70^{\circ}$ and six azimuth orientations, $\phi=0^{\circ}, 45^{\circ}$ and $90^{\circ}$, and $\phi+180=180^{\circ}$, $225^{\circ}$ and $270^{\circ}$. The latter allowed measurement at negative tilt angles. Diffracted data was collected using a 2-D Våntec 500 gas detector. The HAp diffraction peak corresponding to the crystallographic plane (213) at $\mathrm{d}=1.841170 \AA$ $\mathrm{was}$ used to measure residual strain. Assuming validity of the Kroner-Eshelby grain interaction model, the X-ray elastic constants (XECs) $S_{1}$ $=-2.48$ and $\frac{1}{2} S_{2}=11.5 \cdot 10^{-6} \mathrm{MPa}^{-1}$ were used for stress determination. The XECs were calculated using reported literature single crystal constants for hydroxyapatite [25]. Data was analysed with LEPTOS v6 software.

\subsection{Bulk Characterisation}

For through-thickness characterisation of the coating down to the coating-substrate interface, diffraction measurements in transmission geometry were carried out at the $3^{\text {rd }}$ generation Advanced Photon Source's X-ray Operation and Research 6-ID-D beamline at Argonne National Laboratory (ANL), using high energy (70-130 keV) X-rays. The beamline was an undulator monochromatic radiation source with an energy resolution $\Delta \mathrm{E} / \mathrm{E}$ of $4 \times 10^{-4}$. High energy X-ray $(100 \mathrm{keV}, \lambda=0.123331 \AA$ ) were utilised in the experiment. 
The short wavelength allows covering the full diffraction range of both coating and substrate. A small beam spot of $35(\mathrm{~V}) \times 400(\mathrm{H}) \mu \mathrm{m}$, obtained by slits manipulation, was used in probing the samples. Prior to the experiment, a thin slice of the original sample was prepared. This was required to minimize intensity attenuation and possible stress relaxation, to optimise detector resolution, and to ensure the presence of sufficient material required for satisfactory statistics. Although intensity attenuation was not a critical factor considering the penetration power of the radiation, a thick slice would compromise detector resolution [26]. Figure 1 shows the attenuation lengths of the synchrotron radiation in HAp and Ti6Al4V alloy as a function of the photon incidence energy. It is evident that at $80 \mathrm{keV}\left(8 \cdot 10^{4} \mathrm{eV}\right)$, the radiation significantly penetrates both materials with little attenuation. Taking into account the abovementioned factors, a compromise thickness of $6 \mathrm{~mm}$ was selected. The slice was cut using an ISOMET cutter, equipped with a diamond blade. A sample slice was cut from the same batch but was not the same sample as measured with the 8 and $11 \mathrm{keV}$ radiations. To minimise cutting-induced heating, the wheel was set at a low-speed of $150 \mathrm{rpm}$ and the sample was continuously lubricated in emulsion. Figure 2 shows the geometry of the as-received sample and the piece cut for high-energy diffraction measurements. Stepwise measurements, with the incident beam at $90^{\circ}$, were carried out by moving the sample into the beam path in steps of 35 $\mu \mathrm{m}$, covering both the coating thickness and part of the substrate. The diffracted radiation was recorded using a 345-mm diameter 2-D MAR image plate detector (marXperts $\mathrm{GmbH}$, Norderstedt, Germany; pixel size of $100 \times 100 \mu \mathrm{m}^{2}$ ) located approximately $1 \mathrm{~m}$ downstream from the sample as shown in Figure 3. The total time for read-out and erasure was $108 \mathrm{~s}$. The sample was measured at three lateral points labelled $\mathrm{x} 0, \mathrm{x} 4$ and $\mathrm{x} 8$ along the edge of the cut slice (Figure 2c), separated by $4 \mathrm{~mm}$. 
Measurements were done with the $400 \mu \mathrm{m}$ long side of the beam parallel to the coating surface with normal stresses $\sigma_{11}$ and $\sigma_{33}$ directions coinciding with coating-substrate interface line and the through-thickness direction respectively, as shown in Fig 4. Only one azimuth orientation was measured.

\subsection{XRD crystallinity determination}

The relative crystallinity of the coating was calculated as the ratio of the integrated intensity of all crystalline peaks $I_{c}$ and the total integrated intensity $I_{t}$, i.e., the sum of amorphous 'hump' and crystalline peaks,

$$
\% \text { crystallinity }=\frac{I_{c}}{I_{t}}
$$

where $I_{t}=I_{a}+I_{c}$, with $I_{a}$ integrated intensity of the amorphous hump and $I_{c}$ integrated intensity of the crystalline phases. Although adopted from the procedure developed by Keller and Dollase [27], in which the mass fraction of ACP, $\mathrm{x}$ in a mixture of unknown proportions was obtained from the measured amorphous 'hump' area that was found to be a linear function of its proportion in the sample (see also [28]), no corrections on the measured intensity ratio values in the current study was done due to the unavailability of reference mixture data. The method also deviates from conventional ISO 13779-3 and ASTM F2024 standards

To confirm the accuracy of the amorphous content of the sample, the background contribution from the direct beam was subtracted from the diffraction data before crystallinity calculations. The background pattern intensity E was taken with a direct X-ray beam without the sample. The diffraction patterns of the sample were taken as a function of depth $S(z)$ and corrected according to 


$$
S_{c}(z)=S(z)-T(z)^{*} E
$$

where $T$ is the sample transmission. This was measured as a function of depth, and at this energy (100 keV), the transmission was found to be $\sim 1$.

\subsection{Theory of 2D XRD stress determination}

The stress in a polycrystalline sample effects a change in the spacing of the diffracting lattice planes. Whereas in 1-D diffractometry this change is reflected by a shift of the corresponding diffraction peak position, in 2-D X-ray diffractometry $\left(\mathrm{XRD}^{2}\right)$ the presence of residual stresses within the sample is reflected by the distortion of the corresponding Debye rings. The strain tensor $\varepsilon_{\mathrm{ij}}$, determined in the sample coordinate system, and the distortion of the diffraction ring in a particular direction $(\eta, 2 \theta)$ are related by the two-dimensional fundamental equation

$$
f_{11} \cdot \varepsilon_{11}+f_{12} \cdot \varepsilon_{12}+f_{22} \cdot \varepsilon_{22}+f_{13} \cdot \varepsilon_{13}+f_{23} \cdot \varepsilon_{23}+f_{33} \cdot \varepsilon_{33}=\ln \left(\frac{\sin \theta_{0}}{\sin \theta}\right)
$$

where $f_{i j}$ are the strain coefficients, $\ln \left(\frac{\sin \theta_{0}}{\sin \theta}\right)$ is the diffraction cone distortion for a particular $(\eta, 2 \theta)$ position, and $\theta_{0}$ is the peak position for the stress-free material. Using Hooke's law and assuming isotropic conditions, the above equation can be expressed in terms of the stress tensor components as

$$
p_{11} \sigma_{11}+p_{12} \sigma_{12}+p_{13} \sigma_{13}+p_{22} \sigma_{22}+p_{23} \sigma_{23}+p_{33} \sigma_{33}=\ln \left(\frac{\sin \theta_{0}}{\sin \theta}\right)
$$

where $\mathrm{p}_{\mathrm{ij}}$ are constants. This equation can be reduced further in the case of a biaxial stress state. The theory of stress determination employing $\mathrm{XRD}^{2}$ has been well documented, see for example Refs. [29, 30]. 


\subsection{Data analysis}

Before the data could be analysed, the MAR image plate detector was calibrated for geometrical effects and distortions. This was done using a silicon standard sample measured under the same conditions as those of the sample to be investigated, and the data was analysed with the help of an automated MATLAB program [31]. The process was carried out in three steps:

a) The program first bins the data into radially symmetric multiple slices of required thickness with the 2-D data subsequently being transformed from polar coordinates to a rectangular coordinate system. A macro was written to carry out this step. A small step size increases the chance of observing deviatory strain, however, at the expense of an increase in processing time and a reduced number of grains contributing toward a given diffraction peak.

b) The reduced data are $\eta$-integrated for selected diffraction rings into a 1-D diffraction profile, and fitted with a mathematical function to determine peak positions. Figure 5 shows an example of $\eta$ and $2 \theta$ integration of an image plate diffraction ring. In the case of a biaxial stress state, the peak position at $\eta=0^{\circ}$ will be identical to $\eta=180^{\circ}$, and similar for $\eta=90^{\circ}$ and $\eta=270^{\circ}$. In order to obtain the strain tensor components, the peaks were fitted as a function of detector azimuth. The fit assumes a linear $d$ vs. $\sin ^{2} \psi$ behaviour as a starting assumption. This means that three-quarters of the values for a complete diffraction ring are not unique and therefore serve to improve the counting statistics.

c) Lastly, all peak positions calculated by the previous step are used to solve the 2-D fundamental equation (3) using least-square fitting. The error in peak positions calculated from the previous step is propagated to calculate the error of strain components as well as of the $\chi^{2}$ goodness-of-fit tests. The latter is the normalized sum of the squares of the differences between the fit of the strain equation and the peaks positions. This error was calculated 
assuming a Gaussian error distribution, which is a built-in function in the MATLAB fitting routine.

\section{Results}

\subsection{SEM}

Figure 6 shows scanning electron micrographs of the hydroxyapatite feedstock powder used for deposition. The micrograph shows the grains to be irregular in shape with closer examination revealing the grains to constitute a rather loose agglomerate of small crystallites, resulting in a porous microstructure (Figure 6b). Figure 7a shows a typical scanning electron micrograph of the surface of plasma-sprayed HAp coatings that is characterised by smooth glassy, i.e. amorphous regions, cracks running across the surface, and by solidified splats of fully or partially melted individual particles. In addition to the above-mentioned features, fine particles, pores and gaps, formed as a result of poor cohesive bonding between the splats, can be observed across the coating thickness as shown in Fig. 7b.

\subsection{Phase analysis}

Figure 8a-c show the diffraction patterns of the feedstock powder and coatings collected with 8, 11, and $100 \mathrm{keV}$ radiations, respectively. Figure $8 \mathrm{c}$ is a superposition of the pattern collected at different depths below the coating surface including the near-surface regions of the substrate. As reported by other investigators (for example Refs. [32, 33], the high temperature of the plasma jet induces thermal decomposition of the starting HAp material, resulting in the formation of TTCP, TCP, and occasionally $\mathrm{CaO}$. Phase identification results at the probed depths below the coating surface show these phases to be present (Fig. 8). 
The two top patterns of Fig. $8 \mathrm{c}$ show Ti6Al4V to be the predominant phase at a depth of 245 $\mu \mathrm{m}$ indicating that probing extended to the substrate. Figure 9 shows the variation of the phase composition of the plasma-sprayed coatings with depth at the three measured points across the coatings thickness. The last two diffraction patterns in Fig. 9c were omitted due to difficulties with refinement achieving convergence. The results were corrected for amorphous contributions within the coating by subtracting amorphous content. As evident from the figure, HAp and TTCP are the two major phases with the former showing some concentration fluctuation in the near-surface region. Figure 10 shows the variation of the phase composition with depth averaged over the three lateral measuring points. The two major phases present show an opposite trend with depth, indicating a decrease of HAp from around $\sim 75 \mathrm{wt} \%$ at the near-surface region to $\sim 15 \mathrm{wt} \%$ at the coating-substrate interface region, a reduction of about 80\%. The low data point of HAp at $35 \mu \mathrm{m}$ can be considered an outlier. In contrast, with exception of the first two points the TTCP concentration increased from $\sim 6 \mathrm{wt} \%$ to $\sim 8 \mathrm{wt} \%$ (an increase of $\sim 33 \%$ ). Both $\beta$-TCP and $\mathrm{CaO}$ concentrations decreased strongly within the first $40 \mu \mathrm{m}$ before remaining more or less constant to a depth of $180 \mu \mathrm{m}$, and then decreasing again.

\subsection{Crystallinity}

The feed stock powder was crystalline, with the manufacturer reporting a relative value of $100 \%$. Figure 11a shows the variation of coating crystallinity with coating depth at the three measurement points chosen. As for HAp, the crystallinity shows some scatter within the first $40 \mu \mathrm{m}$ that converges with depth below the surface. Figure $11 \mathrm{~b}$ shows the averaged crystallinity over the three measured points across the spraying direction as a function of coating depth, obtained by conventional $\mathrm{X}$-ray at $8 \mathrm{keV}$ as well as $2^{\text {nd }}$ generation synchrotron radiation at $11 \mathrm{keV}$ and $3^{\text {rd }}$ generation synchrotron radiation at $100 \mathrm{keV}$. 
The data show a reduction in crystallinity with depth, with the near-surface region predominantly crystalline at $\sim 93 \%$ and decreasing steadily with depth to $\sim 53 \%$ at the coatingsubstrate interface region, a decrease by $43 \%$. This is in accord with the notion that the molten hydroxyapatite particles impinging at the substrate surface will be quenched rapidly and solidify predominately as amorphous calcium phosphate (ACP), whereas later arriving particles cool more slowly owing to the limited thermal conductivity of the already deposited hydroxyapatite layer (see for example, Ref. [33]). The apparent increase in crystallinity at $\sim 210 \mu \mathrm{m}$ can be attributed to the underlying substrate peaks, as seen in the diffraction pattern in Fig. 8c.

By examining the data shown in Fig. 11, it is noteworthy to mention that there exists a significant difference between the crystallinity values measured with a conventional X-ray diffractometer and with synchrotron radiation. This may indeed signify that conventional diffractometer measurements prescribed by standards such as ASTM F2024, allowing the pattern to be acquired on an as-deposited coating, and ISO 13779-3 that requires that the coating be detached and ground into powder to account for through-thickness variations of crystallinity, should be taken with a grain of salt. It may well be that the "true" crystallinity is lower than conventional diffractometer measurements would suggest. This fact could have severe repercussion on the validity of quality control of biomedical implant coatings that impose minimum requirements on coating crystallinity as expressed in the ISO 13779-3 standard. 


\subsection{Residual stress analysis}

Figure 12 show the $\sin ^{2} \psi$ plots for the six azimuth angles collected with the $8 \mathrm{keV}$ radiation. The plots are generally linear with some curvature at low tilts. No clear indication of psi splitting is observed. Figure 13 reports the distribution of residual stress components and the stress amplitude $\left(\sigma_{11}-\sigma_{33}\right)$ measured at the three lateral points chosen and their variation with depth below the coating surface. Since only one azimuth orientation was measured, only three stress components, i.e. $\sigma_{11}, \sigma_{13}, \sigma_{33}$ could be determined. The stress amplitude $\left(\sigma_{11}-\sigma_{33}\right)$ is a useful means to eliminate misalignment effects between different samples. The plots can generally be divided into two regions, I and II, above and below the central axis (around 140 $\mu \mathrm{m})$, respectively. The three stress components at the different lateral points show agreement within error bars in region I, but significant scatter in region II, predominately at the coatingsubstrate interface region.

Figure 14 shows the distribution of the average stress, determined using conventional $\mathrm{CuK} \alpha$ X-ray and synchrotron radiations. The two independent stress components $\sigma_{11}$ and $\sigma_{13}$ are generally small and indicate tensile stress and clockwise direction of shear, respectively in both I and II regions that relax steadily in the former to a neutral axis around $\sim 110 \mu \mathrm{m}$ followed by a steady increase in region II to a maximum of $\sim+46$ and $\sim+23 \mathrm{MPa}$, respectively. The normal component $\sigma_{33}$ indicates compressive stress that increases with depth to $\sim-34 \mathrm{MPa}$ in the same region. With further depth, the stress state changes from compressive to tensile, increasing with depth to a maximum of $+56 \mathrm{MPa}$. 


\section{Discussion}

\subsection{Phase composition}

The observed distribution of phases and the variation of crystallinity with depth can be explained in terms of the temperature gradient that exists during coating build-up. Plasmasprayed coatings are composed of layers deposited splat-by-splat during each pass made by the torch. Hence, the entire coating is composed of a multitude of lamellae/splats deposited one after the other and on top of each other, respectively. Those hydroxylapatite particles that are fully melted during plasma spraying will solidify during cooling on the substrate surface. Considering that the first deposited layer heats up the substrate to a temperature $T_{1}$, the second to a temperature $T_{2}, \ldots$ the $n^{\text {th }}$ to a temperature $T_{n}$, the net effect will be the development of a phase composition commensurate with such a temperature gradient across the coating thickness. For the first lamella deposited on the pristine substrate, the cooling rate of a molten HAp particle on the comparatively cold metallic substrate is maximum. The large temperature difference between the impinging molten drops and the substrate leads to high cooling rates in excess of $10^{6} \mathrm{~K} / \mathrm{s}$ (for example Refs. $[33,34]$ ). The nature of the resulting phases therefore depends on the cooling rate. As nucleation is impeded during rapid quenching, high cooling rates produce amorphous calcium phosphate (ACP). The phase compositions shown in Figs. 7 to 9 are consistent with previously reported work (see for example Refs. $[13,35,36]$. The data scatter observed within the first $35 \mu \mathrm{m}$ among the three measured points can be attributed to a possible dissolution of coating material due to the emulsion lubricant used during cutting of the slice. The apparent increase in crystallinity beyond $175 \mu \mathrm{m}$ shown in Fig. 11 is attributed to contribution from the overlapping substrate peaks. 
Since each subsequent deposit heats up the previously deposited layer, the temperature difference as well as the cooling rate decrease continuously. On the one hand, the increasing temperature during deposition means less quenching of the subsequently arriving droplet, resulting in reduction in amorphicity, i.e. increased crystallinity as the coating thickens. On the other hand, the incoming droplet will "anneal" the previously quenched phases, provided the temperature is high enough. Under such condition, the always-present thermal decomposition products may reconstruct to form HAp. Reheating of powders consisting of thermal decomposition products quenched from $1500{ }^{\circ} \mathrm{C}$ produced direct reconstruction of HAp from TTCP at around $400^{\circ} \mathrm{C}$ whilst $\alpha$-TCP transformed to $\beta$-TCP react with $\mathrm{Ca}(\mathrm{OH})_{2}$ to form more HAp [37, 38]. In addition, despite the high temperature encountered during plasma spraying, ACP still contains substantial amounts of protons and $\mathrm{OH}^{-}$ions as revealed by electron energy loss spectroscopy (EELS; [33]). These residual ions are thought to act as a driving force for the (partial) crystallisation of ACP to hydroxylapatite during cooling [13].

A number of possible factors influencing the data can be attributed to the significant discrepancies among the TTCP concentrations obtained with the $8 \mathrm{keV}$ and $11 \mathrm{keV}$, and the high-energy synchrotron radiation as shown in Fig 10b. As indicated in section 2.2, these factors include i) measurements carried out with conventional and synchrotron radiations were done on two samples from the same batch, ii) sample orientation using conventional Xray radiation focused on the geometrical centre of the samples whilst that of the synchrotron radiation was slightly off-centre, and iii) the irradiated area using the former was at least 45 times larger than using the latter.

Another important aspect to consider pertains to coating thickness. In the present work, relatively thick coatings were deposited and investigated. It is well known that a thin HAp layer $(<50 \mu \mathrm{m})$ yields better adhesion compared with thicker coatings [39], owing to reduced 
residual coating stress [40]. However, this stress will be quickly relaxed in the course of bone integration. Thicker coatings $( \pm 150 \mu \mathrm{m})$ show substantially reduced adhesion strength but may be required in some instances to ensure a more permanent bond to guarantee implant stability by a lasting biological effect. This is particularly evident when during an endoprosthetic replacement operation involving an exchange of the implant the cortical bone matter has been previously damaged, often in concurrence with an undesirable geometric configuration of the implant-supporting bone [41]. In this special case, a thin, quickly resorbed calcium phosphate coating will not be sufficient to sustain the required large-scale bone regeneration. Hence, thicker coatings will be required to stimulate bone reconstruction over longer times.

\subsection{Residual stress profile in HAp coatings}

The distribution of the stress observed in regions I and II of Fig. 14 can be attributed to a net sum of stresses originating from quenching (also known as intrinsic stress), differential thermal mismatch of the coating and substrate as expressed by the difference in the coefficient of thermal expansion (also known as thermal or cooling stress), and the stress arising from volume change associated with phase transformation. However, based on the slight change in the content of TTCP i.e. $6 \mathrm{wt} \%$ to $8 \mathrm{wt} \%$, as shown in Fig 10b, it can be concluded that contribution of the latter to the final stress is minimal. With both the quenching and thermal stresses tensile due to, frozen-in splat contraction during cooling to substrate temperature upon deposition and the higher thermal coefficient of the deposit $\left(\alpha_{\mathrm{HAp}}=11.5 \times 10^{-6} \mathrm{~K}^{-1}\right)$

compared to that of the substrate $\left(\alpha_{\mathrm{Ti} A \mathrm{Al} 4 \mathrm{~V}}=8.9 \times 10^{-6} K^{-1}\right)$ [42] respectively, the final stress state across the coating is be expected to be tensile. However, with ceramic coating materials, the quenching stress, as predicted and reported by Tsui et al [43,44] and Kuroda et al [45], is expected to be small and constant over the coating thickness. The stress distribution shown in 
Figs 13 and 14 are therefore mainly related to the contribution of thermal stress with the maximum magnitude that can be accommodated without coating failure given by,

$$
\sigma_{t h}=\left[\frac{E}{1-v}\right]\left(\alpha_{c}-\alpha_{s}\right) \Delta T,
$$

where $E$ is Young's modulus, $v$ is Poisson's ratio, $\alpha_{c}$ and $\alpha_{s}$ are the thermal expansion coefficients of coating and substrates, respectively and $\Delta T$ is the temperature difference between the final and initial states. Note that depending on the sign of $\left(\alpha_{c}-\alpha_{s}\right)$, the thermal stress can be tensile or compressive.

The observed $\sigma_{11}$ stress distribution in the current study, see Fig. 14a, is consistent with the above argument as well as Finite Element Analysis computational results obtained by Cofino et al. [46]. Although the $8 \mathrm{keV}$ obtained stress value is slightly higher, it is integrated within the trend. The higher value can be attributed to the fact that being near-surface, the magnitude is not affected by the deposition of subsequent layer(s) hence more tensile. On the other hand the observed $\sigma_{33}$ stress distribution, see Fig. 14c, is consistent with synchrotron measurement findings reported in the same study [46], which showed, in general, a compressive stress state across region I and part of region II, turning tensile with increasing depth below the surface. Given that the top surface of the sample is a free surface and restrain of the through-thickness deformation is not expected; the significant $\sigma_{33}$ values in Fig. $14 \mathrm{c}$ can therefore not only be attributed to Poison effect: various other factors also contributes. These include effects of thermal gradient across coating thickness during deposition [47], a possible gradient in quenching stress due to e.g. different interlamellar bonding, intralamellar microcracking, and open gaps well as different mechanical strengths of the intralamellar materials. This is evident from the heterogeneous microstructure observed across the coating thickness, see Fig. $7 \mathrm{~b}$. The possible discrepancies and differences relating to the non linear distribution of stress components, Figs 13 and 14, as opposed to the linear through-thickness stress distribution predicted by the analytical model of Tsui et al [44], based on constant quenching stress 
assumption, can be attributed to the presence of amorphous calcium phosphate and the observed non uniform microstructure amongst other. The results obtained in this study also show consistency with findings of Tsui et al [43] who, using curvature technique, reported tensile stress of around $40 \mathrm{MPa}$ for HA coated Ti-6Al-4V substrate sprayed at $36 \mathrm{~kW}$ and are comparable with ultimate tensile strength of HAp coatings, which ranges between 40 and 60 $\operatorname{MPa}[48]$.

\section{Conclusions}

Depth-resolved studies employing both conventional X-rays and synchrotron radiations were carried out on air plasma-sprayed HAp coatings.

a) Phase identification results showed thermal decomposition products to be present throughout the coating thickness. Quantitative Rietveld analyses showed the distribution trend with depth of the two major phases, HAp and TTCP, to be opposite. The amount of hydroxyapatite decreased from $\sim 53 \mathrm{wt} \%$ at the near-surface region to $\sim 15 \mathrm{wt} \%$ adjacent to the coating-substrate interface region, whereas the amount of tetracalcium phosphate increased from $\sim 6 \mathrm{wt} \%$ to $8 \mathrm{wt} \%$ in the same range with significant changes occurring in the first $60 \mu \mathrm{m}$.

b) The crystallinity distribution shows a trend similar to HAp, decreasing from $93 \%$ in the near-surface region to $53 \%$ at the coating-substrate interface region.

c) The stress components $\sigma_{11}$ and $\sigma_{13}$ are tensile and indicate clockwise direction of shear, respectively and relax to zero within the first $110 \mu \mathrm{m}$, but increase with further depth steadily to reach maxima at $\sim+20$ and $\sim+10 \mathrm{MPa}$, respectively. In contrast, $\sigma_{33}$ is compressive and first increases to $\sim-30 \mathrm{MPa}$ slightly deeper in the coating, but 
changes further in depth to tensile, reaching a maximum of $+15 \mathrm{MPa}$ at the coating surface. 


\section{Acknowledgements}

Use of the Advanced Photon Source (APS) at Argonne National Laboratory (ANL) was supported by the U.S. DOE under Contract No. DE-AC02-06CH11357. The authors are indebted to Mrs Margitta Hengst, Department of Mineralogy, Technische Universität Bergakademie Freiberg, Germany for providing the plasma-sprayed samples, Drs Douglas Robinson and Jonathan Almer, ANL/APS for assisting with experimental set up, and data acquisition and analysis, respectively; Mr. Ryno van der Merwe and Dr. Gawie Nothnagel, NECSA for microscopy analysis and proof reading, respectively. The research work was sponsored by the German Federal Ministry of Education and Research (BMBF) and the National Research Foundation of the Republic of South Africa within the research project "Characterisation and determination of residual stress in bioactive coatings and layered structure" (Project code 39.6.G0B.6.A). 


\section{References}

[1] T. Yamamoto, T. Onga, T. Marui, K. Mizuno, Use of hydroxyapatite to fill cavities after excision of benign bone tumours, J. Bone Joint Surg. (Br.), 82B, (2000) 1117.

[2] T. Colen, Comparison of artificial eye amplitudes with acrylic and hydroxyapatite spherical enucleation implants, Ophthalmology, 107 (2000) 1889.

[3] R.G.T. Geesink, K. de Groot, C.P.A.T. Klein, Chemical implant fixation using hydroxylapatite coatings The development of a human total hip prosthesis for chemical fixation to bone using hydroxyl-apatite coatings on titanium substrates, Clin. Orthop. Relat. Res., 225 (1987) 147.

[4] K. de Groot, R. Geesink, C.P.A.T. Klein, P. Serekian, Plasma sprayed coatings of hydroxylapatite, J. Biomed. Mater. Res., 21 (1987) 1375.

[5] K.A. Thomas, Hydroxyapatite coatings, Orthopaedics, 1994, 267.

[6] R.B. Heimann, H.D. Lehmann, Bioceramic Coatings for Medical Implants. Trends and Techniques. Wiley-VCH, Weinheim, Germany. 2015. 467 pp.

[7] R. McPherson, A review of microstructure and properties of plasma sprayed ceramic coatings, Surf. Coat. Technol., 39/40 (1989) 173.

[8] S. Takeuchi, M. Ito, K. Takeda, Modelling of residual stress in plasma-sprayed coatings: Effect of substrate temperature, Surf. Coat. Technol., 43/44(1) (1990) 426.

[9] S. Dyshlovenko, B. Pateyron, L. Pawlowski, D. Murano, Numerical simulation of hydroxyapatite powder behaviour in plasma jet, Surf. Coat. Technol., 179 (2004) 110.

[10] Y.C. Yang, E. Chang, Measurements of residual stresses in plasma-sprayed hydroxyapatite coatings on titanium alloy, Surf. Coat. Technol., 190(2) (2005) 122.

[11] R.B. Heimann, Thermal Spraying of Biomaterials, Sur. Coat. Technol., 201 (2006) 2012.

[12] M. Topić, T. Ntsoane, T. Hüttel, R.B. Heimann, Microstructural characterisation and stress determination in as-plasma sprayed and incubated bioconductive hydroxyapatite coatings, Surf. Coat. Technol., 201(6) (2006) 3633.

[13] K.A. Gross, C.C. Berndt, H. Herman, Amorphous phase formation in plasma-sprayed hydroxyapatite coatings, J. Biomed. Mater. Res., 39 (1998) 407.

[14] Y.C. Yang, B.C. Wang, E. Chang, J.D. Wu, The influence of plasma spraying parameters on the characteristics of hydroxyapatite coatings: a quantitative study, J. Mat. Sci.: Mater. Med., 6 (1995) 249.

[15] P. Ducheyne, S. Radin, L. King, The effect of calcium phosphate ceramic composition and structure on in vitro behavior. I Dissolution, J. Biomed. Mater. Res., 27 (1993) 25.

[16] S.R. Radin, P. Ducheyne, Plasma spraying induced changes of calcium phosphate ceramic characteristics and the effect on in vitro stability, J. Mat. Sci.: Mater. Med., 3 (1992) 33. 
[17] W. Xue, S. Tao, X. Liu, X. Zheng, C. Ding, In vivo evaluation of plasma sprayed hydroxyapatite coatings having different crystallinity, Biomaterials, 25 (2004) 415.

[18] T.P. Ntsoane, M. Topic, R. Bucher, Near-surface in-vitro studies of plasma sprayed hydroxyapatite coatings, Powder Diffr., 26, Special Iss. 02 (2011) 138.

[19] Y.C. Yang, E. Chang, S.Y. Lee, Mechanical properties and Young's modulus of plasmasprayed hydroxyapatite coating on Ti substrate in simulated body fluid, J. Biomed. Mater. Res., 67A (2003) 886.

[20] B.C. Wang, E. Chang, T.M. Lee, C.Y. Yang, Changes in phase and crystallinity of plasma-sprayed hydroxyapatite coatings under heat treatment: A quantitative study, J. Biomed. Mater. Res., 29 (1995) 1483.

[21] R.B. Heimann, T.P. Ntsoane, C.A. Pineda-Vargas, W.J. Przybylowicz, M. Topić, Biomimetic formation of hydroxyapatite investigated by analytical techniques with high resolution, J. Mat. Sci.: Mater. Med., 19 (2008) 3295.

[22] Y.C. Yang, E. Chang, Residual stress in plasma-sprayed hydroxyapatite coating measured by layer removal method, J. Mater. Sci. Lett., 22 (2003) 919.

[23] J. Wen, Y. Leng, J. Chen, C. Zhang, Chemical gradient in plasma-sprayed HA coatings Biomaterials, 21 (2000) 1339.

[24] C. Giles, F. Yokaichiya, S.W. Kycia, L.C. Sampiao, D.C. Ardiles-Saravia, M.K.K. Franco, R.T. Neuenschwander, High resolution X-ray diffraction beamline at the LNLS for the study of charge, orbital and magnetic structures, J. Synchr. Rad., 10 (2003) 430.

[25] T.N. Gardner, J.C. Elliot, Z. Sklar, G.A.D. Briggs, Acoustic microscope study of the elastic properties of fluorapatite and hydroxyapatite, tooth enamel and bone, J. Biomech., 25 (1992) 1265.

[26] J. Boehm, A. Wanner, R. Kampmann, H. Franz, K.-D Liss, A. Schreyer, H. Clemens, Internal stress measurements by high-energy synchrotron x-ray diffraction at increased specimen-detector distance, Nucl. Instr. Meth. Phys. Res. B, 200 (2003) 315.

[27] L. Keller, W.A. Dollase, X-Ray determination of crystalline hydroxyapatite to amorphous calcium-phosphate ratio in plasma sprayed coatings, J. Biomed. Mater. Res., 49 (2000) 244.

[28] R.B. Heimann, Characterisation of as-sprayed and incubated hydroxyapatite coatings with high resolution techniques, Materialwiss. Werkstofftech., 40 (1-2) (2009) 21.

[29] A. Wanner, D.C. Dunand, Methodological aspects of the high-energy synchrotron x-ray diffraction technique for internal stress evaluation, J. Neutr. Res., 9 (2001) 495.

[30] B.B. He, U. Preckwinkel, K.L. Smith, Fundamentals of two-dimensional X-ray diffraction $\left(X^{2} D^{2}\right)$, Adv. X-ray Anal., 43 (2000) 273.

[31] J. Almer, U. Lienert, Advance Photon Source, Argonne National Laboratory, Personal communication.

[32] L. Sun, C.C. Berndt, R.S. Lima, A. Kucuk, K.A. Khor, Effect of spraying parameters on phase formation and distribution in plasma-sprayed hydroxyapatite, Proc. Intern. Thermal Spray Conf., 2000, 803-811. 
[33] R.B. Heimann, R. Wirth, Formation and transformation of amorphous calcium phosphate on titanium alloy surfaces during atmospheric plasma spraying and their subsequent in vitro performance,.Biomaterials, 27 (2006) 823.

[34] H. Ji, C.B. Ponton, P.M. Marquis, Microstructural characterization of hydroxyapatite on titanium, J. Mater. Sci.: Mater. Med., 3 (1992) 1133.

[35] K.A. Gross, C.C. Berndt, Thermal processing of hydroxyapatite for coating production, J. Biomed. Mater. Res., 15(39) (1998) 580.

[36] R.B. Heimann, Tracking the thermal decomposition of plasma-sprayed hydroxylapatite, Am. Min., 100 (2015) 2419.

[37] C.J. Liao, F.H. Lin, K.S. Chen, J.S. Sun, Thermal decomposition and reconstruction of hydroxyapatite in air atmosphere, Biomaterials, 20 (1999) 1807.

[38] F.H. Lin, C.J. Liao, K.S. Chen, J.S. Sun, Thermal reconstruction behavior of the quenched hydroxyapatite powder during reheating in air, Mater. Sci. Eng. C, 13 (2000) 97.

[39] E. Wintermantel, S.W. Ha, Biokompatible Werkstoffe und Bauweisen. Implantate für Medizin und Umwelt. Springer, Berlin, Heidelberg, Tokyo. 1996, p. 225.

[40] R.B. Heimann, Structure, Properties, and Biomedical Performance of Osteoconductive Bioceramic Coatings, Surf. Coat. Technol., 233 (2013) 27.

[41] R.B. Heimann, N. Schürmann, R.T. Müller, In vitro and in vivo performance of Ti6Al4V implants with plasma-sprayed osteoconductive hydroxylapatite-bioinert titania bond coat "duplex" systems: an experimental study in sheep. J. Mater. Sci.: Mater. Med., 15 (2004) 1045.

[42] G. Bauer, CRC Handbook of Bioactive ceramics vol. 1, CRC press, Boca Raton, FL.1990, p81

[43] Tsui YC, Doyle, Clyne TW, Plasma sprayed hydroxyapatite coatings on titanium substrate Part 1. Mechanical properties and residual stress levels, Biomaterials 1998, 19, 2013-2029;

[44] Tsui YC, Doyle, Clyne TW, An analytical model for predicting residual stresses in progressively deposited coatings Part 1: Planar geometry, Thin Solid Films, 1997, 306, 23-33

[45] S. Kuroda, T.W. Clyne, The quenching stress in thermally sprayed coatings, Thin Solid Films, 200 (1991) 49.

[46] B. Cofino, P. Fogarassy, P. Millet, A, Lodino, Thermal residual stresses near the interface between plasma-sprayed hydroxyapatite coating and titanium substrate: Finite element analysis and synchrotron radiation measurements, J Biomed Mater Res A, 2004, 1-70

[47] L. Pawlowski, M. Vardelle, P. Fauchais, A model of the temperature distribution in an alumina coating during plasma spraying, Thin Solid Films, 94, 1982, 307-319

[48] TK Chaki, PE Wang, Densification and strengthening of silver-reinforced hydroxyapatite matrix composite prepared by sintering. J. Mater. Sci.: Mater. Med., 5 (1994) 553-542. 


\section{Tables}

Table 1: Plasma spray parameters $($ slpm $=$ standard litres per minute $)$

\section{Figures}

Figure 1: Total cross-section attenuation length as a function of incidence energy: a) HAp coating, b) Ti6Al4V alloy.

Figure 2: Geometry and dimensions of the sprayed HAp coating a) original disc, b) cut slice and c) cut slice indicating measured points.

Figure 3: Schematic diagram illustrating high-energy X-ray diffraction measurements in transmission geometry; the axes triad indicates the three directions.

Figure 4: Schematic diagram illustrating the orientation of the X-ray beam in relation to the sample and the normal stress directions.

Figure 5: a) Typical 2-dimensional diffraction pattern illustrating $\eta$ and $2 \theta$-integration, b) converted conventional 1-D pattern.

Figure 6: Scanning electron micrographs of hydroxyapatite feedstock powder taken at different magnification.

Figure 7: Scanning electron micrograph of a typical as-sprayed HAp coating: a) top surface, b) cross-section.

Figure 8: Diffraction patterns of HAp coatings, superposed with feedstock powder, plotted in d-spacing: a) $8 \mathrm{keV}$ conventional $\mathrm{X}$-ray, b) $11 \mathrm{keV} 2^{\text {nd }}$ generation synchrotron radiation, and c) representative $100 \mathrm{keV} 3^{\text {rd }}$ generation synchrotron radiation of the different lateral points; the marked spacing indicates measurement points below the surface. The patterns show the presence of HAp (o), tetracalcium phosphate (\#), tricalcium phosphate $(\bullet)$ and $\mathrm{CaO}(*)$. 
Figure 9: Variation of phase composition in wt $\%$ with depth measured at the three lateral points perpendicular to the spraying direction: a) HAp, b) TTCP, c) $\beta$-TCP, and d) $\mathrm{CaO}$.

Figure 10: Variation of phase composition (spatial average of Fig. 9 superposed with conventional X-ray, $2^{\text {nd }}$ and $3^{\text {rd }}$ generation synchrotron data) of HAp coatings with depth: a) HAp, b) TTCP, c) TCP and d) $\mathrm{CaO}$.

Figure 11: Crystallinity variation in HAp coating: a) at the three lateral points perpendicular to the spraying direction and $\mathrm{b}$ ) averaged spatially resolved data obtained by conventional Xray $(8 \mathrm{keV}), 2^{\text {nd }}$ and $3^{\text {rd }}$ generation synchrotron radiations $(11$ and $100 \mathrm{keV})$.

Figure 12: $\operatorname{Sin}^{2} \psi$ plots for the different azimuth angles collected with $8 \mathrm{keV}$ radiations.

Figure 13: Variation of residual stress tensor components with depth at the three lateral points perpendicular to the spray direction: a) $\sigma_{11}$, b) $\sigma_{13}$, c) $\sigma_{33}$ and d) stress amplitude $\sigma_{11}$ $\sigma_{33}$. The dotted lines show the change from compressive (region I) to tensile (region II) mode beyond $120-140 \mu \mathrm{m}$.

Figure 14: Variation of residual stress tensor components, averaged over the lateral points perpendicular to the spray direction, with depth at the three: a) $\sigma_{11}$, b) $\sigma_{13}$, c) $\sigma_{33}$ and d) stress amplitude $\sigma_{11}-\sigma_{33}$. The dotted lines indicate the change from compressive (region I) to tensile (region II) mode beyond about $120 \mu \mathrm{m}$. 
Table 1:

\begin{tabular}{|c|c|}
\hline Parameter & Value \\
\hline Primary plasma gas (Ar) & $45 \mathrm{slpm}$ \\
\hline Secondary plasma gas $\left(\mathrm{H}_{2}\right)$ & $6.5 \mathrm{slpm}$ \\
\hline Carrier gas $(\mathrm{Ar})$ & $5 \mathrm{slpm}$ \\
\hline $\begin{array}{c}\text { Relative powder feed rate } \\
\text { Relative hopper stirrer } \\
\text { rotation rate }\end{array}$ & $20 \%$ of maximum \\
\hline $\begin{array}{c}\text { Stand-off distance } \\
\text { Plasma power }\end{array}$ & $90 \mathrm{~mm}$ \\
\hline Horizontal speed & $0.1 \mathrm{~m} / \mathrm{s}$ \\
\hline Traverse speed & $0.017 \mathrm{~m} / \mathrm{s}$ \\
\hline
\end{tabular}




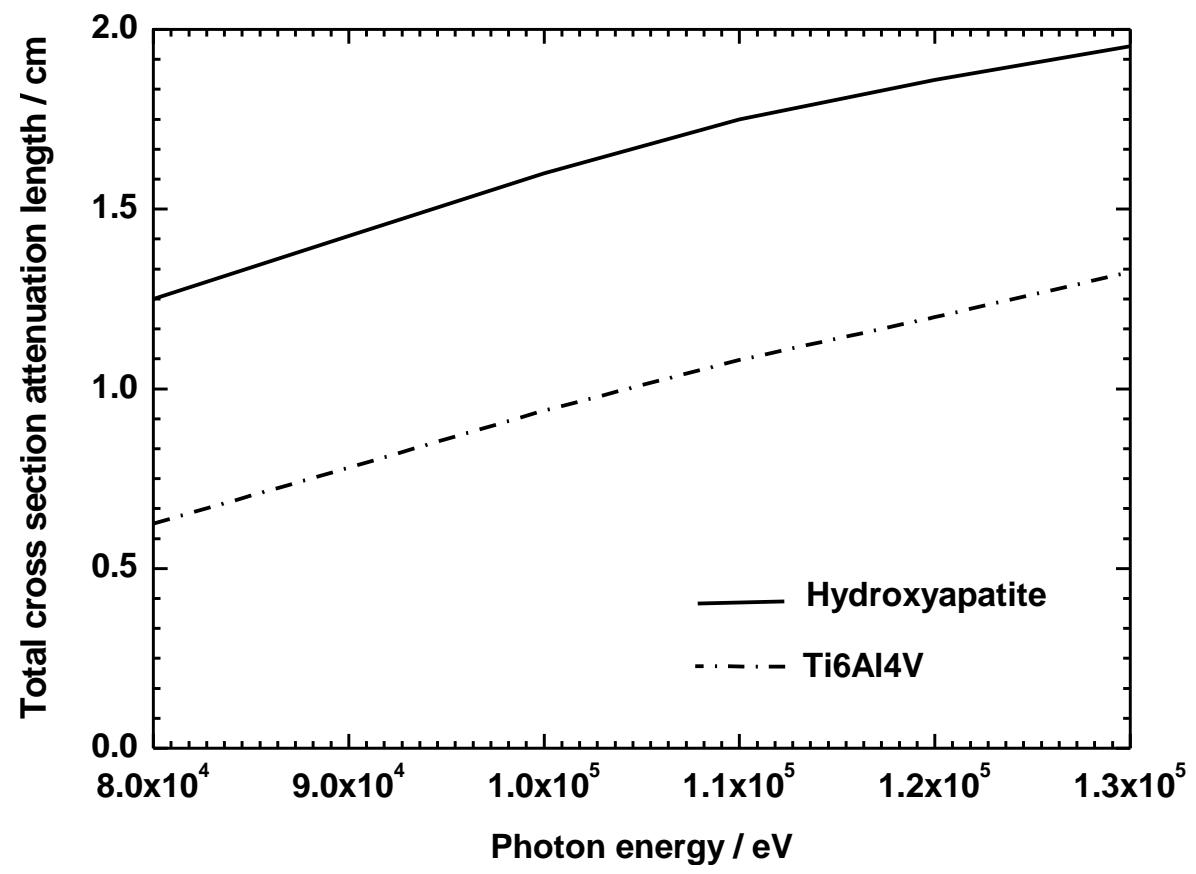

Figure 1

As-sprayed disc

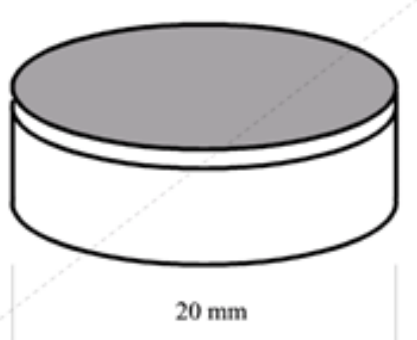

(a)

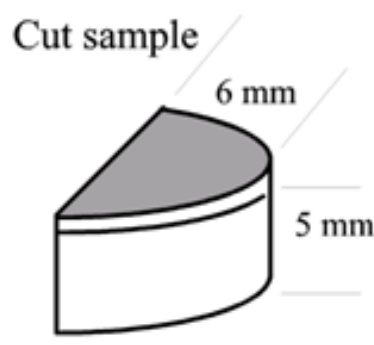

(b)

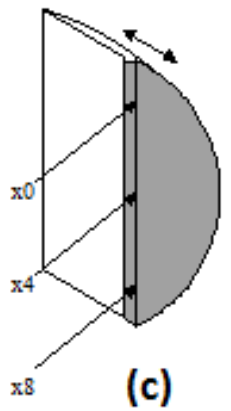

(c)

Figure 2 


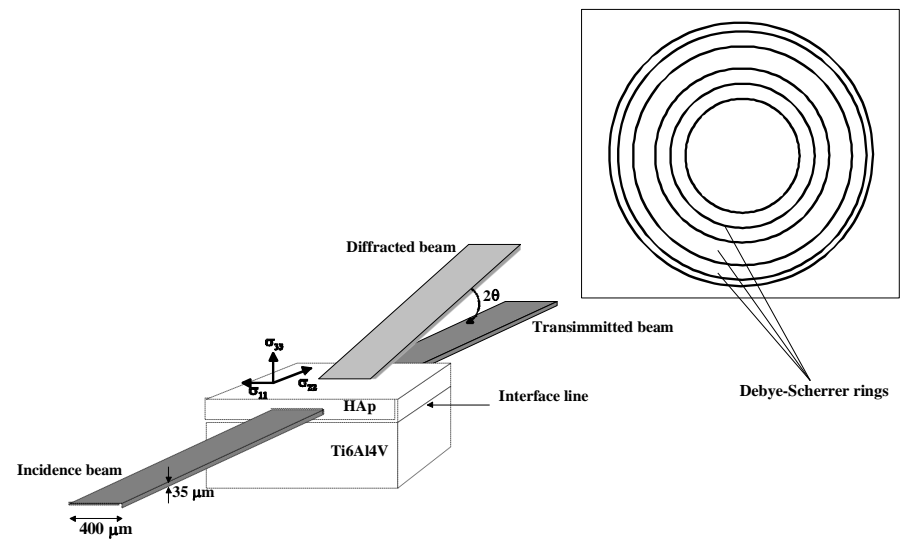

Figure 3

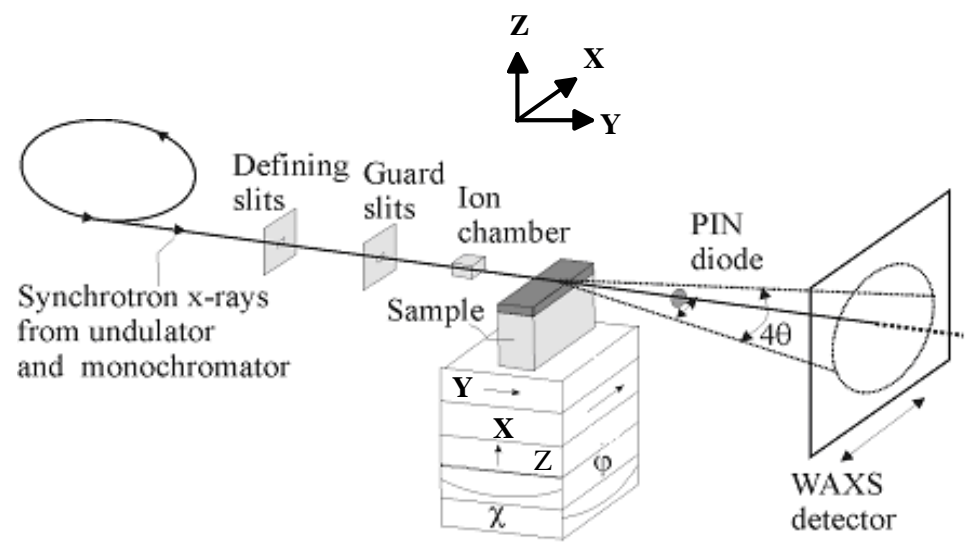

Figure 4
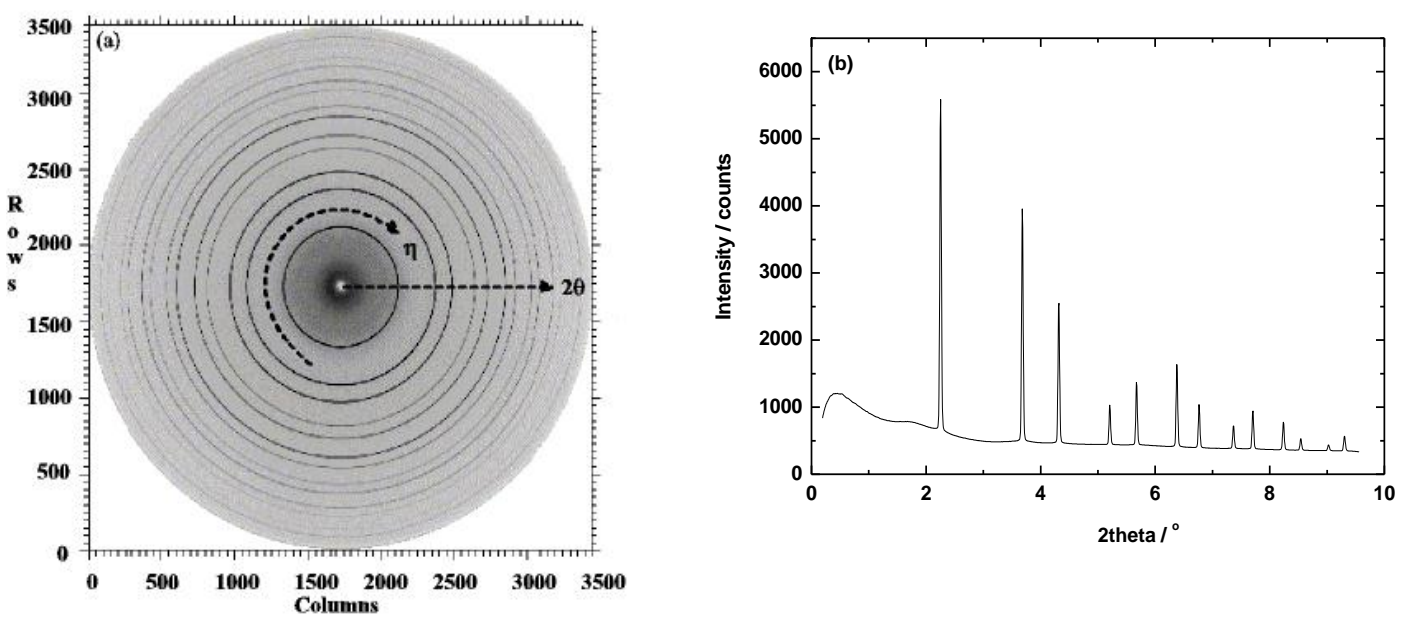

Figure 5 

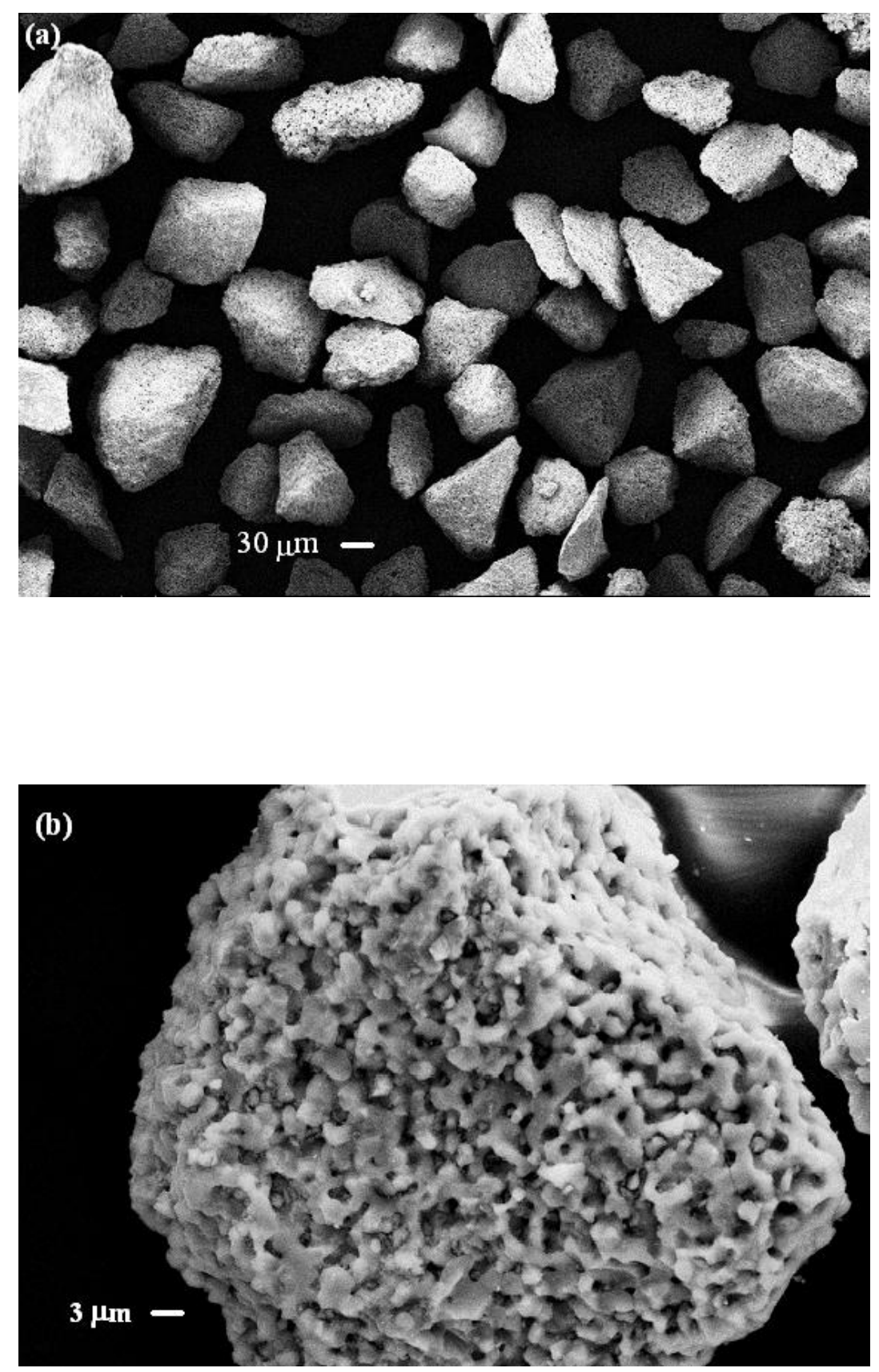

Figure 6 

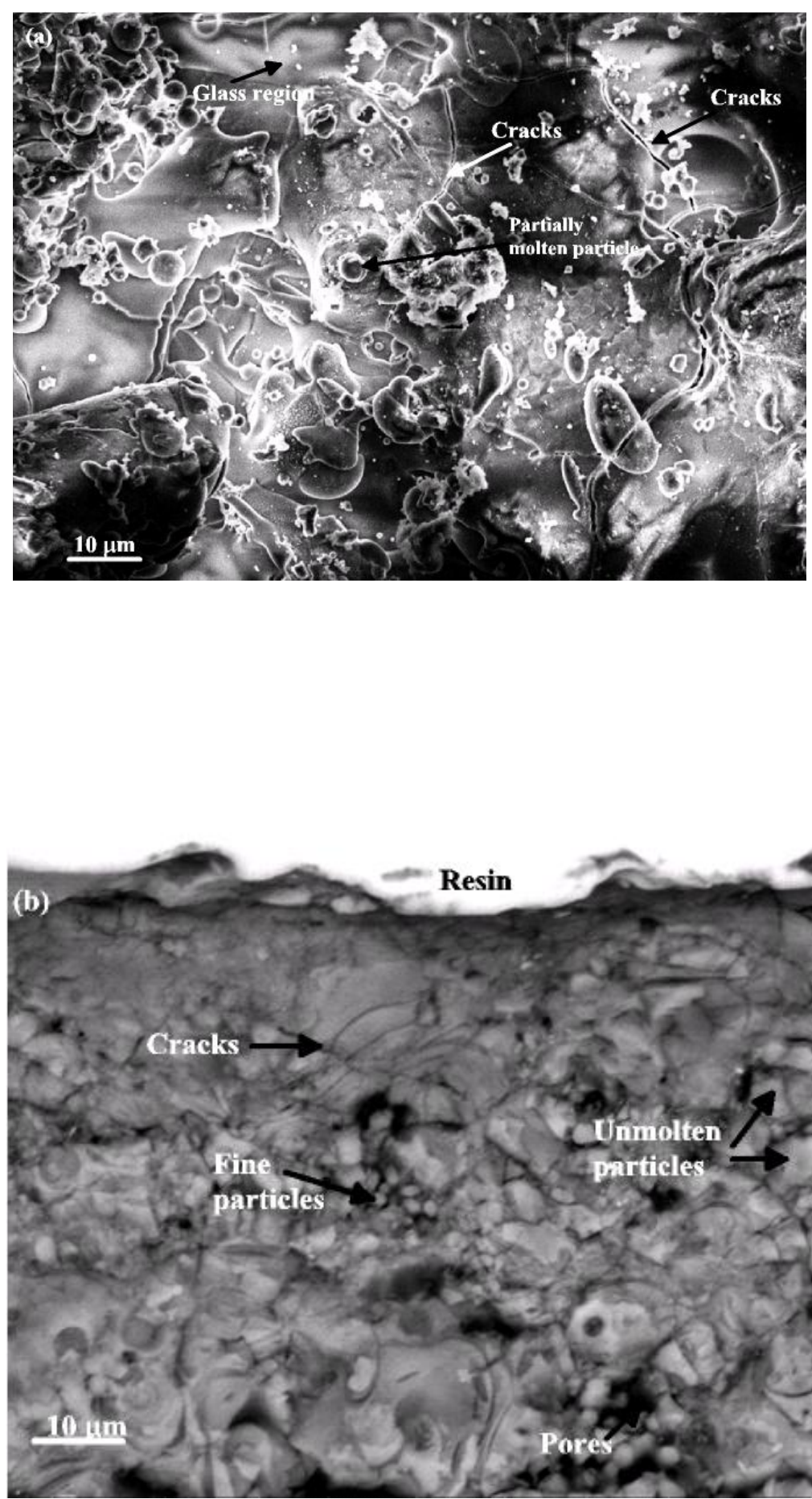

Figure 7 

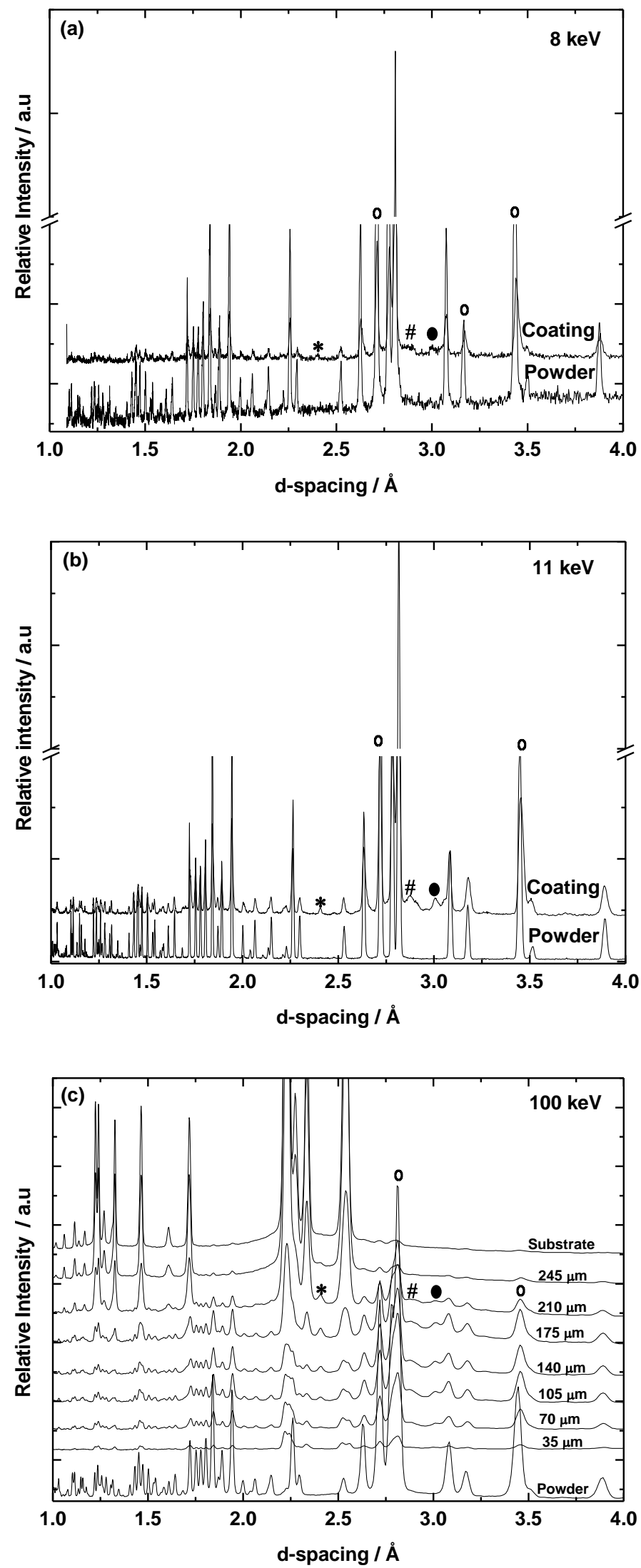
Figure 8

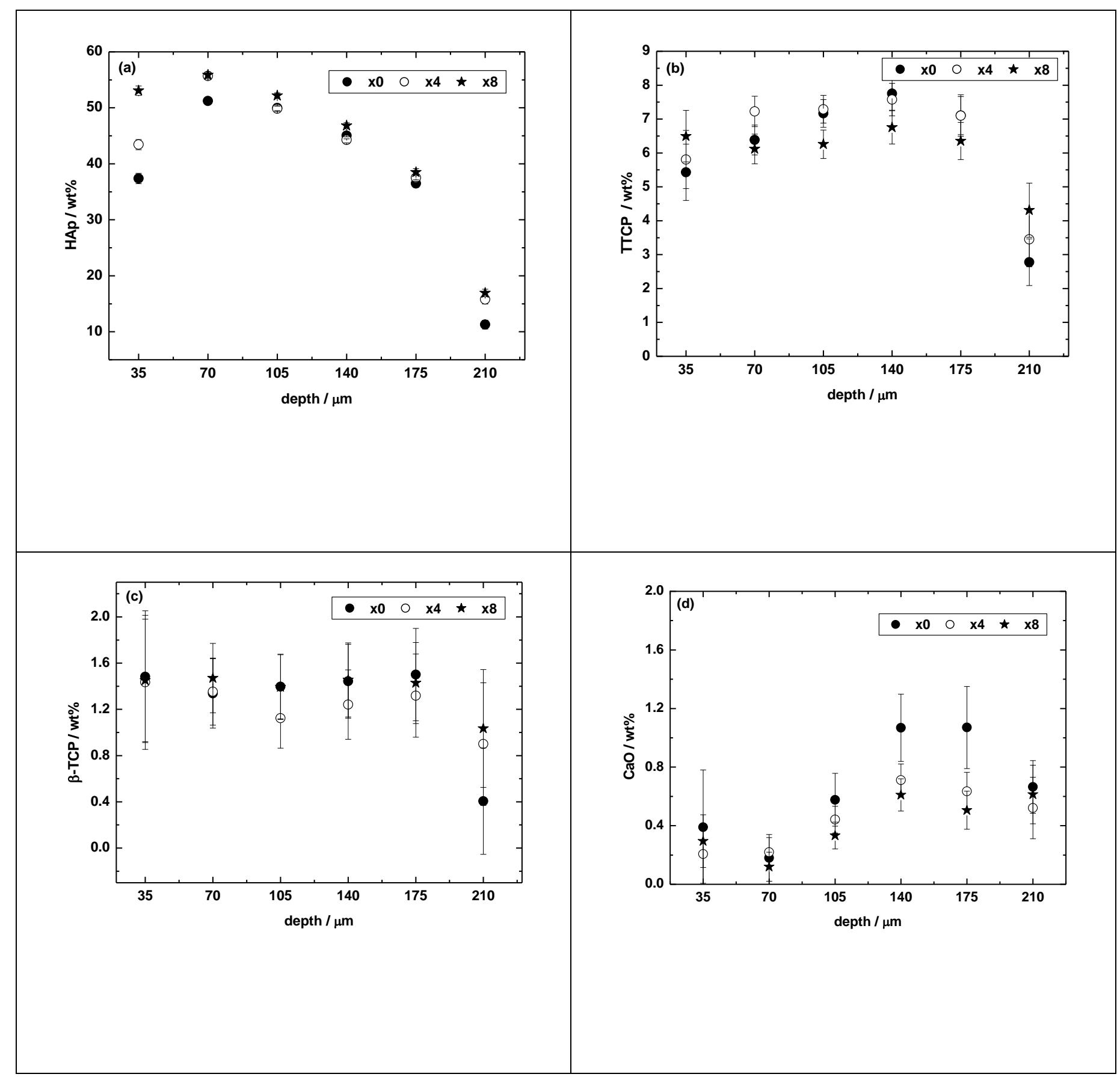

Figure 9 


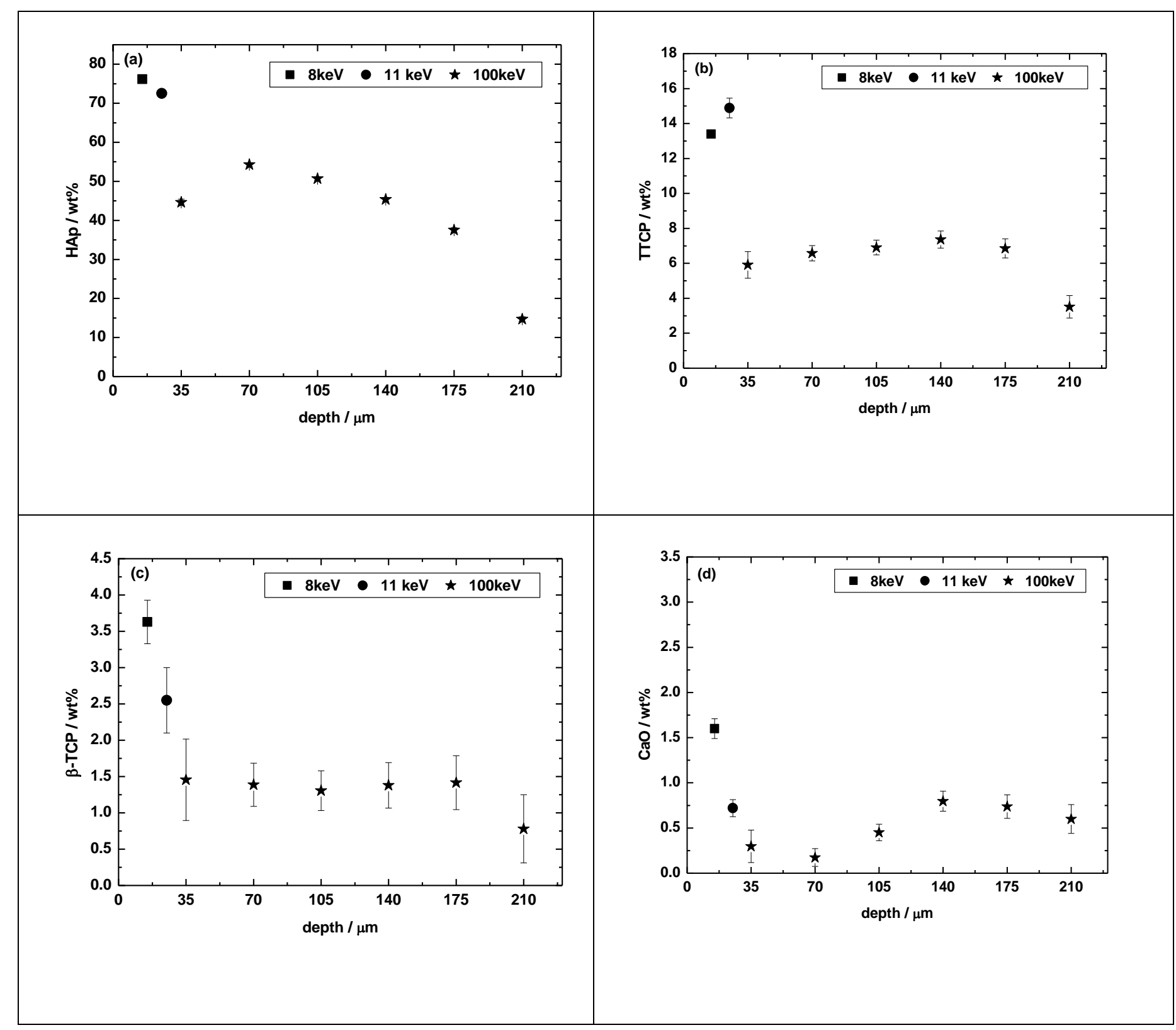

Figure 10 


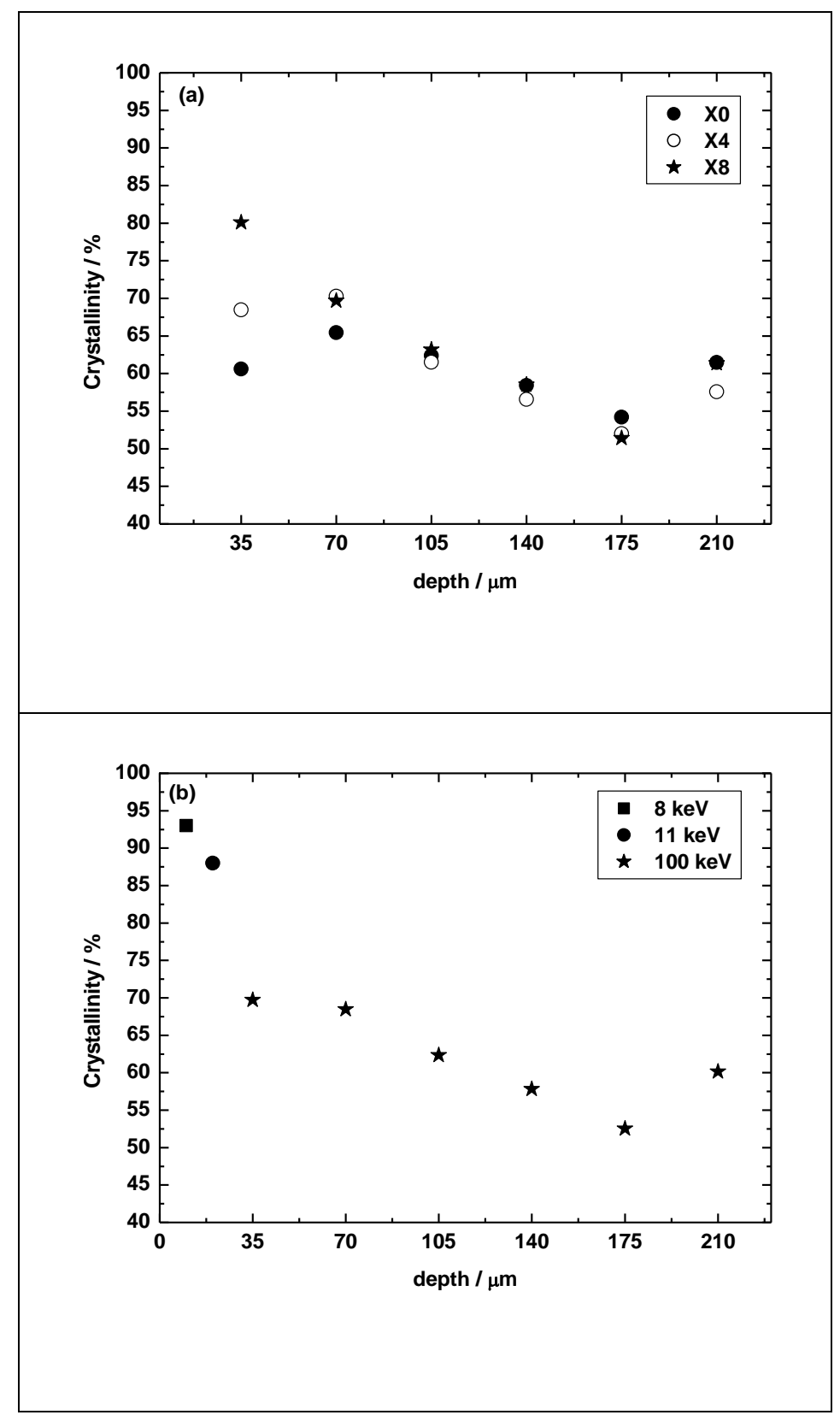

Figure 11 


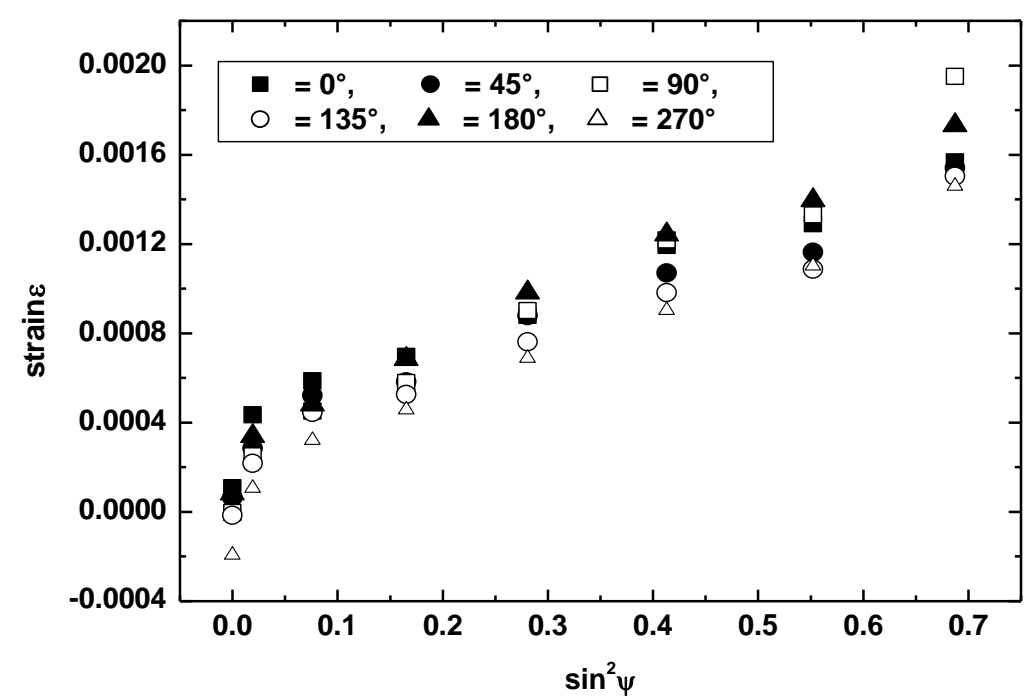

Figure 12 


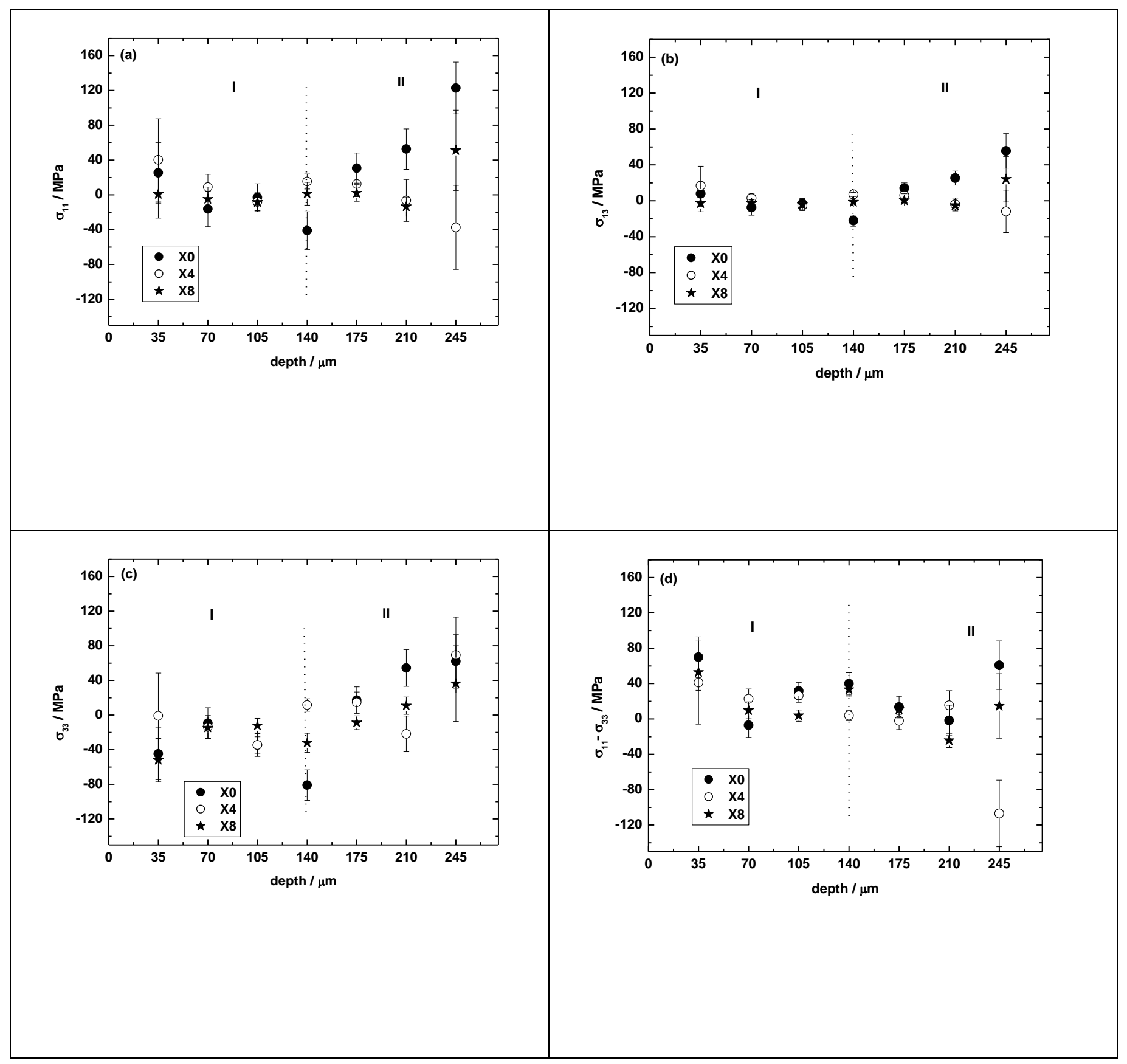

Figure 13 


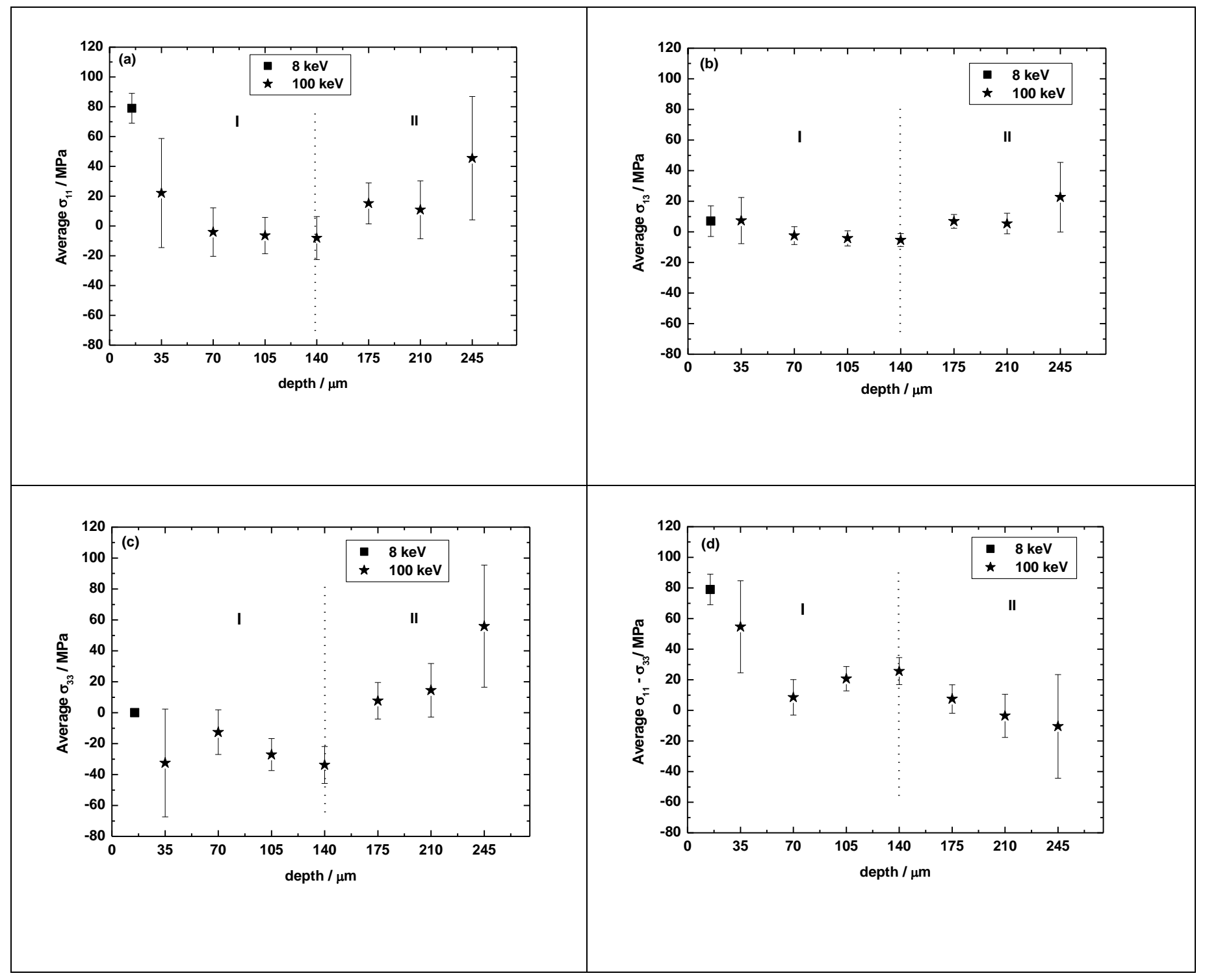

Figure 14 